\title{
Time and temperature dependence of granulocyte damage by leucotoxic supernatants from Pasteurella haemolytica A1
}

\author{
B. StYrt, ${ }^{1,2 *}$ R. D. WAlker, ${ }^{2}$ L. D. DahL ${ }^{2}$ and A. Potter ${ }^{3}$ \\ 1,2 Departments of Medicine ${ }^{1}$ and Microbiology and Public Health ${ }^{2}$, Michigan State University, East Lansing, \\ MI 48824, USA \\ ${ }^{3}$ VIDO, University of Saskatchewan, Saskatoon, Saskatchewan, Canada
}

(Received 26 March 1990; revised 11 July 1990; accepted 18 July 1990)

\begin{abstract}
Bacterial exotoxins may contribute to the pathogenic potential of micro-organisms through interactions with cells of the host defence system as well as by directly damaging host tissue. The present studies were designed to explore mechanisms of interaction between bovine granulocytes and the leucotoxin produced by Pasteurella haemolytica, a major cause of bovine respiratory disease. Leucotoxin-containing supernatant from $P$. haemolytica Al caused rapid cell death in isolated bovine granulocytes that was close to half-maximal by $5 \mathrm{~min}$ and nearly $90 \%$ complete after 30 min at $37^{\circ} \mathrm{C}$. Maintaining granulocytes at ice-water temperature markedly attenuated or prevented the toxic effect; furthermore, if exposed to supernatants at ice-water temperature and then washed, most cells remained viable even after rewarming to room temperature. However, even a very brief exposure (about $5 \mathrm{~s}$ ) at $37^{\circ} \mathrm{C}$ led to extensive cell death even after immediate cold dilution and washing. Granule enzymes such as arylsulphatase were released far more slowly than cytosol contents. Leucotoxin purified by column chromatography showed temperature dependence and divergence between cytosol and granule marker release similar to those observed with the crude supernatant preparation. These findings indicate that irreversible interaction between $\boldsymbol{P}$. haemolytica leucotoxin and bovine granulocytes is initiated very rapidly at $37^{\circ} \mathrm{C}$ but markedly impeded at low temperature, while granule enzyme release follows cytosol marker release over a much longer period. The results suggest either a requirement for target cell metabolic activity to initiate toxin effects or a temperature-dependent receptor conformation, with granule enzyme release following as a secondary consequence of granulocyte death.
\end{abstract}

\section{Introduction}

Exotoxin release is among the major factors contributing to virulence in bacterial infections. Well-recognized modes of action of bacterial exotoxins include direct interactions such as host-cell destruction by membrane lysis, inhibition of host cell metabolism by interference with protein synthesis, and host cell energy depletion by exhaustion of energy-rich phosphates. Exotoxins may also play an indirect role in pathogenesis by interacting with cells of the host defence system to decrease the microbicidal efficacy of these defensive cells and induce secondary host tissue damage through release of toxic metabolites or enzymes from the cells of primary host defence. Bovine pneumonic pasteurellosis represents an

\footnotetext{
Abbreviations: IEF, isoelectric focusing; LDH, lactate dehydrogenase.
}

0001-6151 (C) 1990 SGM intriguing model for these latter categories of indirect exotoxin action because the pathogen, Pasteurella haemolytica, releases a leucotoxin active against several leucocyte types in susceptible species (Chang et al., 1986; Chang \& Renshaw, 1986; Clinkenbeard et al., 1989; Kaehler et al., 1980; O'Brien \& Duffus, 1987). Challenge studies have suggested that neutrophils are a major component of the pulmonary response (Walker et al., 1985) and that neutrophil depletion protects calves against at least one phase of the lung damage which is characteristic of this infection (Breider et al., 1988; Slocombe et al., 1985). Modification of neutrophil function may therefore play an important role in pathogenesis. The possible participation of the leucotoxin in this process is not well understood at this time, but a role in virulence may be suspected, as with other bacteria that release toxins active against phagocytes (Densen \& Mandell, 1980). 
To delineate the contribution of $P$. haemolytica leucotoxin to the pathogenessis of pulmonary infection, it is important to elucidate the mechanisms of interaction between this toxin and susceptible host leucocytes. Understanding these mechanisms may also provide insight into the action of other bacterial exotoxins which modify host defence responses in analogous ways. In the studies reported here, we sought to define requirements for initiation of the leucotoxin effect on bovine granulocytes and the time course of cytotoxic effects.

\section{Methods}

Granulocyte isolation. Blood samples were obtained from adult dairy cattle by venipuncture using heparinized syringes. Granulocytes were separated from mononuclear leucocytes by Histopaque (Sigma) density gradient centrifugation as in our previous studies (Styrt et al., 1990). Erythrocytes were lysed using two or three cycles of hypotonic lysis with $0.2 \%(\mathrm{w} / \mathrm{v}) \mathrm{NaCl}$, followed by addition of an equal volume of $1.6 \%$

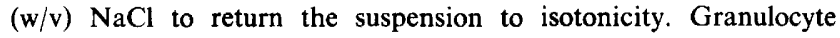
purification was checked in selected experiments using Wright differential staining. Isolated granulocytes were resuspended in Hanks' balanced salt solution at concentrations approximating 5 to $6 \times 10^{6}$ cells $\mathrm{ml}^{-1}$ for assays for cell viability and marker release. Granulocyte preparations obtained by this method typically consist mostly of neutrophils with a smaller population of eosinophils and occasional contaminating mononuclear cells.

Leucotoxin-containing supernatants. P. haemolytica (biotype A, serotype 1) was originally isolated on Brain Heart Infusion (BHI) agar (supplemented with $1 \%(\mathrm{w} / \mathrm{v})$ yeast extract, $1 \%(\mathrm{v} / \mathrm{v})$ horse serum and $5 \%(\mathrm{v} / \mathrm{v})$ defibrinated sheep blood) from the pneumonic lung of a calf. To maintain its virulence, this organism was subsequently passaged in calves by intrabronchial inoculation. Isolates from the calves were passaged twice on supplemented BHI agar suspended in sterile skim milk, lyophilized and frozen at $-70^{\circ} \mathrm{C}$. Lyophilized stock was reconstituted with sterile distilled water and used to inoculate supplemented BHI plates. Following overnight incubation, BHI broth supplemented with $1 \%$ heat-inactivated horse serum was inoculated with 5 to 10 isolated colonies. The primary broth was incubated overnight in a $37^{\circ} \mathrm{C}$ shaking water bath prior to making a $1 \%$ transfer to RPMI 1640 medium (Gibco) supplemented with $7 \%(\mathrm{v} / \mathrm{v})$ heatinactivated foetal bovine serum. This secondary culture was grown for $5.5 \mathrm{~h}$ in a $37^{\circ} \mathrm{C}$ shaking water bath and then centrifuged for $10 \mathrm{~min}$ at 10000 r.p.m. at $4^{\circ} \mathrm{C}$. The supernatant was harvested, filter-sterilized $(0.22 \mu \mathrm{m})$ and stored in aliquots at $-70^{\circ} \mathrm{C}$. Supernatants which did not kill the great majority of granulocytes at $1: 10$ dilution were discarded as having insufficient leucotoxin activity for appropriate study.

Purified leucotoxin. An overnight culture of $P$. haemolytica A1 strain B122 (Deneer \& Potter, 1989; Potter et al., 1988) was diluted 100-fold into BHI broth (Difco) and shaken at $37^{\circ} \mathrm{C}$ until the $\mathrm{OD}_{660}$ was $1 \cdot 0$. The culture was centrifuged at 5000 r.p.m. in a Sorvall GSA rotor at $4{ }^{\circ} \mathrm{C}$ for $10 \mathrm{~min}$ and the supernatant was filtered through a $0.22 \mu \mathrm{m}$ membrane. This was then frozen in a dry ice/ethanol bath and lyophilized. This material was rehydrated with 0.1 volume of $10 \mathrm{~mm}-$ Tris $/ \mathrm{HCl}, \mathrm{pH} 7.5$, and dialysed for $48 \mathrm{~h}$ against double-distilled water (six changes, $3500 \mathrm{ml}$ each). This crude culture supernatant was fractionated by preparative isoelectric focusing (IEF) along a pH 3 to
10 gradient in a Rotofor IEF apparatus (Bio-Rad) as described by the manufacturer. Each IEF run was for $4 \mathrm{~h}$ at $12 \mathrm{~W}$ constant power. Twenty fractions were collected and a sample of each was tested for leucotoxin activity by lactate dehydrogenase (LDH) release from bovine neutrophils (Korzeniewski \& Callewaert, 1983). Those fractions containing components with pI values between 6.0 and 7.2 were pooled, $\mathrm{NaCl}$ was added to $1 \mathrm{M}$ and the fractions were desalted on Sephadex G25 disposable columns (Pharmacia). Endotoxin was removed by affinity chromatography using a Detoxigel column (Pierce) as described by the manufacturer. Because the purified leucotoxin showed substantial variation in activity, comparative experiments were done with leucotoxin concentrations adjusted to give approximately the same degree of cytotoxicity as the culture supernatants used in analogous settings.

Assays of granulocyte death. Granulocyte death was measured in two ways. Release of the cytosol marker LDH was measured spectrophotometrically by standard methods as described previously (Styrt et al., 1985). Trypan blue dye uptake was measured by adding $0.1 \mathrm{ml} 0.4 \%$ trypan blue in normal saline to $0.1 \mathrm{ml}$ of cell suspension and $0.8 \mathrm{ml}$ phosphate-buffered saline (PBS Dulbecco), and examining microscopically under a coverslip. Cells which stained blue were considered non-viable. Trypan blue dye exclusion was used preferentially to measure cell viability in experiments involving extremely long incubations or extensive dilution of the cell suspension, because the dilution or prolonged incubation tended to result in $\mathbf{L D H}$ activity that was too low to be accurately measured.

Release of granule contents. Release of granule contents was measured by splitting the samples into two equal portions, centrifuging one of the aliquots for $10 \mathrm{~min}$ at $4{ }^{\circ} \mathrm{C}$ and $300 \mathrm{~g}$, and measuring enzyme content in the supernatant. This was compared with total cellular enzyme content in the remaining duplicate aliquot of cells lysed with Triton X-100.

Arylsulphatase was measured fluorometrically by release of 4-methylumbelliferone from its sulphate conjugate (Fluharty \& Edmond, 1978). Incubation was for $30 \mathrm{~min}$ at $37^{\circ} \mathrm{C}$ and fluorescence was read at $365 \mathrm{~nm}$ excitation and $450 \mathrm{~nm}$ emission in an AmincoBowman spectrophotofluorometer. The fluorescent product 4-methylumbelliferone was used to construct standard curves.

Elastase-like activity was measured fluorometrically as release of 7-amino-4-methylcoumarin from MeOSucc-Ala-Ala-Pro-Val-7-amino4-methylcoumarin in a modification of methods described by Sklar $\boldsymbol{e t}$ al. (1982) and Brown \& Roth (1990). Incubation was done for $4 \mathrm{~h}$ at room temperature and the fluorescence generated was compared against 7-amino-4-methylcoumarin standards.

Temperature effects. To determine whether cytotoxicity could be initiated at low temperatures, duplicate samples of cells were incubated with leucotoxic supernatant at $37^{\circ} \mathrm{C}$ or in an ice-water bath. In selected experiments, granulocytes were then washed with cold PBS and allowed to return to room temperature for $30 \mathrm{~min}$ before viability determinations.

For assessment of the cytotoxicity of very brief leucotoxin exposures, granulocytes were warmed to $37^{\circ} \mathrm{C}$ for $5 \mathrm{~min}$ before addition of leucotoxin. Within 5 to $10 \mathrm{~s}$ after leucotoxin addition, the cell suspension was diluted with three volumes of ice-cold PBS, centrifuged and washed a second time with cold PBS. The granulocytes were then resuspended in PBS and rewarmed to $37^{\circ} \mathrm{C}$ for $5 \mathrm{~min}$ before viability determination.

Statistical treatment. Replicate experiments were done at least three times unless otherwise noted in Results. Results are shown as the mean and standard error of the mean for the stated number of experiments (blood drawn on different days or from different animals) unless otherwise indicated, $t$-test analyses (Colton, 1974) were used for evaluations of statistical significance. 


\section{Results}

\section{Time course of cell damage}

Fig. 1 shows cell death measured as failure to exclude trypan blue dye in granulocytes exposed to a 1 in 10 dilution of leucotoxin-containing $P$. haemolytica culture supernatant. The onset of cell damage was very rapid, with half-maximal cytotoxicity in this series of experiments observed after 5 min and nearly $90 \%$ cell death after $30 \mathrm{~min}$ of incubation.

Measurements of cell death were compared using both trypan blue exclusion and LDH release in selected experiments. The two methods gave generally parallel results at incubation times allowing appropriate comparisons. For example, in three experiments paired at 5 , 30 and 60 min time points with or without supernatant, there were no significant differences between percentage cell death determined by failure to exclude trypan blue and $\mathrm{LDH}$ release $(72 \pm 5 \%, 88 \pm 1 \%, 85 \pm 4 \%$ death by trypan blue at 5,30 and $60 \mathrm{~min}$ with supernatant compared with $73.4 \pm 7.7 \%, 96.2 \pm 1.0 \%$, and $95.7 \pm 2.0 \% \mathrm{LDH}$ release). Attempts at incubations of less than 5 min led to poorly comparable results (data not shown) because of the difficulty of stopping the interaction with toxin at a precise time; the cold-dilution methods described below were developed to approach this issue.

\section{Time course of degranulation}

Fig. 2 shows the release of the granule enzyme arylsulphatase. In accordance with our previous findings (Styrt et al., 1990), a much smaller percentage of arylsulphatase was released during the initial incubation period relative to percentage loss of viability. When incubation with leucotoxic supernatant was prolonged, $32.5 \pm 5.3 \%$ of arylsulphatase was released after $4 \mathrm{~h}$ (Fig. $2 a$ ); with overnight incubation (Fig. $2 b$ ) this rose to $81 \cdot 1 \pm 7.0 \%$. A modest excess arylsulphatase release relative to cell death was seen in samples without supernatant after overnight incubation, and was thought possibly attributable to a small number of cells entirely lysed and not detectable on the trypan blue slides, to selective destruction of cells with high arylsulphatase content (e.g. eosinophils), or to active secretion due to stimulation of cells by the very prolonged incubation.

In selected experiments, the release of activity associated with another lysosomal enzyme, elastase, was measured. The supernatant preparations used in this series of experiments had somewhat less leucotoxic activity and granule enzyme release was somewhat higher than in the longer-incubation experiments, but the delay in release of both enzymes relative to

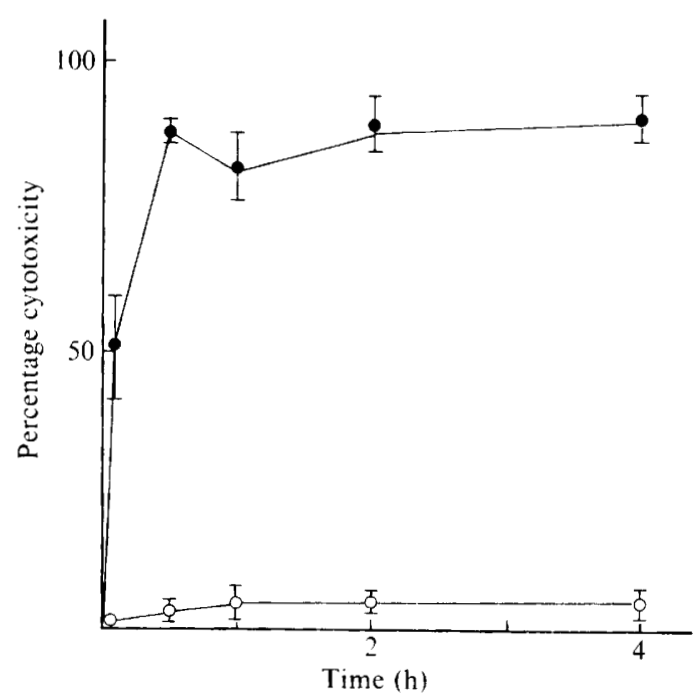

Fig. 1. Cytotoxicity of $P$. haemolytica supernatant ( 1 in 10 dilution) as measured by loss of the ability to exclude trypan blue dye. $\bullet$, Cells exposed to leucotoxic supernatants; $O$, control cells incubated in buffer for the indicated time periods. Mean \pm SEM of 3 to 5 values are shown for each time point, representing experiments with at least $4 \mathrm{~h}$ total incubation and granule enzyme measurements (see Fig. 2) done for comparison.

cytotoxicity was confirmed. Cell death (by trypan blue), arylsulphatase release and release of elastase-like activity were $69 \pm 4 \%, 32.6 \pm 5.8 \%$ and $26.9 \pm 6.4 \%$, respectively at $30 \mathrm{~min}$, and $84 \pm 2 \%, 60.9 \pm 6.4 \%$ and $50 \cdot 2 \pm 9 \cdot 7 \%$, respectively at $2 \mathrm{~h}$ (mean \pm SEM of five experiments; $P<0.001$ for comparison of elastase release with cell death at each time point; $P<0.01$ for arylsulphatase release versus cell death at $30 \mathrm{~min}$ and $P<0.05$ at $2 \mathrm{~h}$ ).

\section{Temperature effects on granulocyte damage}

Although cell death occurred rapidly at $37^{\circ} \mathrm{C}$, granulocytes maintained at ice-water temperature showed much less evidence of damage even after prolonged exposure to leucotoxic supernatants. Fig. 3 shows loss of cell viability assessed by $\mathrm{LDH}$ release following $60 \mathrm{~min}$ of exposure to 1 in 10 dilutions of supernatant in an ice-water bath. Very little cell death was apparent at the end of incubation. Furthermore, if cells exposed to toxin at low temperature for $5 \mathrm{~min}$ were diluted with cold PBS and returned to room temperature, most of the granulocytes $(97 \pm 1 \%)$ remained viable although direct exposure to leucotoxic supernatant at room temperature was highly toxic $(68 \pm 13 \%$ cell death $)$.

In additional experiments, granulocytes were prewarmed to $37^{\circ} \mathrm{C}$, leucotoxic supernatant was added, and the cell suspension was immediately diluted with ice-cold buffer and washed at $4{ }^{\circ} \mathrm{C}$ before rewarming and 

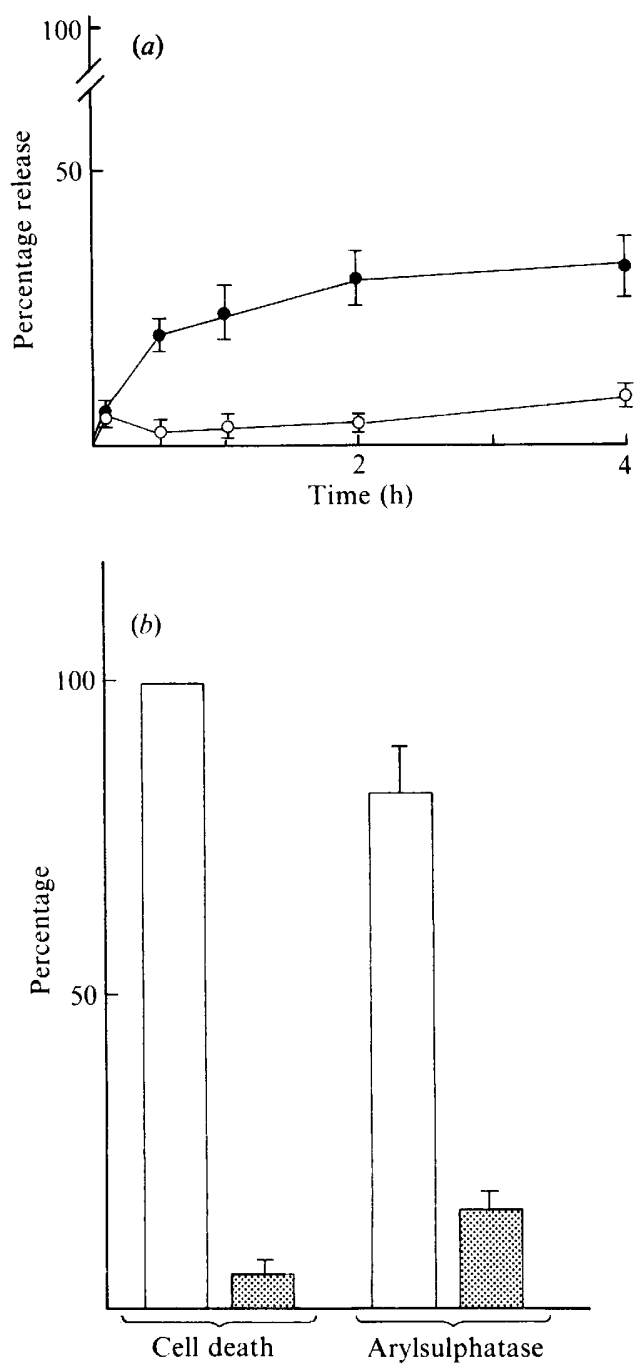

Fig. 2. (a) Percentage release of arylsulphatase in the same experiments as Fig. 1. $\bullet$, Cells exposed to leucotoxic supernatants; $O$, control cells incubated in buffer. (b) Cell death (percentage of cells failing to exclude trypan blue) and percentage of arylsulphatase release in cell suspension incubated overnight with leucotoxic supernatant at 1 in 10 dilution ( $\square$ ) or control buffer (웅). Mean \pm SEM of five experiments.

assessment of viability. Thus, cells were exposed to supernatant for only about 5 to $10 \mathrm{~s}$ at $37^{\circ} \mathrm{C}$ before being chilled and washed. In contrast to the results observed when cells were kept cold throughout the period of supernatant exposure, Fig. 4 shows that even momentary exposure at $37^{\circ} \mathrm{C}$ led to cell damage which could not be prevented or reversed by washing.

\section{Effects of purified leucotoxin}

Selected experiments were replicated using the small quantities of purified leucotoxin available. As shown in Fig. 5(a), three experiments using a $30 \mathrm{~min}$ incubation

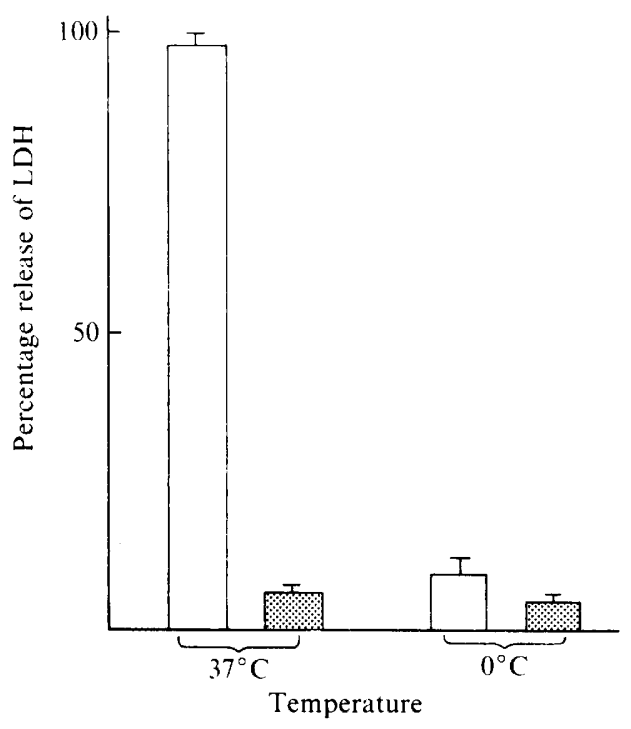

Fig. 3. Percentage release of $\mathrm{LDH}$ following $60 \mathrm{~min}$ of exposure to leucotoxic supernatant $(\square)$ or control buffer (웅 at $37^{\circ} \mathrm{C}$ or $0{ }^{\circ} \mathrm{C}$. Mean \pm SEM of four experiments. $P<0.001$ for toxin-induced release at $37^{\circ} \mathrm{C}$ versus $0{ }^{\circ} \mathrm{C}$.

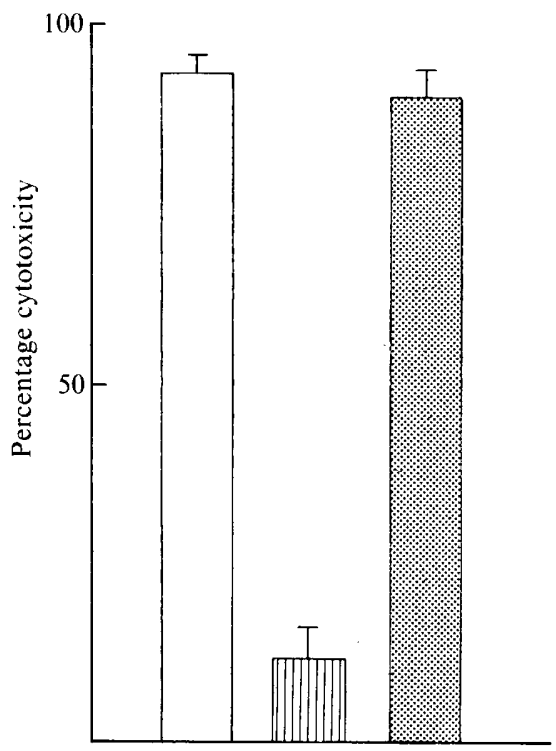

Fig. 4. Percentage cell death (failure to exclude trypan blue) after exposure to 1 in 10 dilution of leucotoxic supernatant at $37^{\circ} \mathrm{C}$ or $0{ }^{\circ} \mathrm{C}$ followed by immediate dilution with $37^{\circ} \mathrm{C}$ or $0{ }^{\circ} \mathrm{C}$ buffer, washing, and incubation at $37^{\circ} \mathrm{C}$ for $5 \mathrm{~min}$. $\square$, Exposure and dilution at $37^{\circ} \mathrm{C}$; 面, exposure and dilution at $0{ }^{\circ} \mathrm{C}$; 0 , exposure at $37^{\circ} \mathrm{C}$ and dilution at $0{ }^{\circ} \mathrm{C}$. Mean \pm SEM of five experiments. $P<0.001$ for comparison of either right or left bar with centre bar.

with the purified toxin (at concentrations giving cell death comparable to that observed with culture supernatants) produced a similar divergence between cell death and arylsulphatase release. As shown in Fig. 5(b), momentary exposure to the purified toxin at $37^{\circ} \mathrm{C}$ 


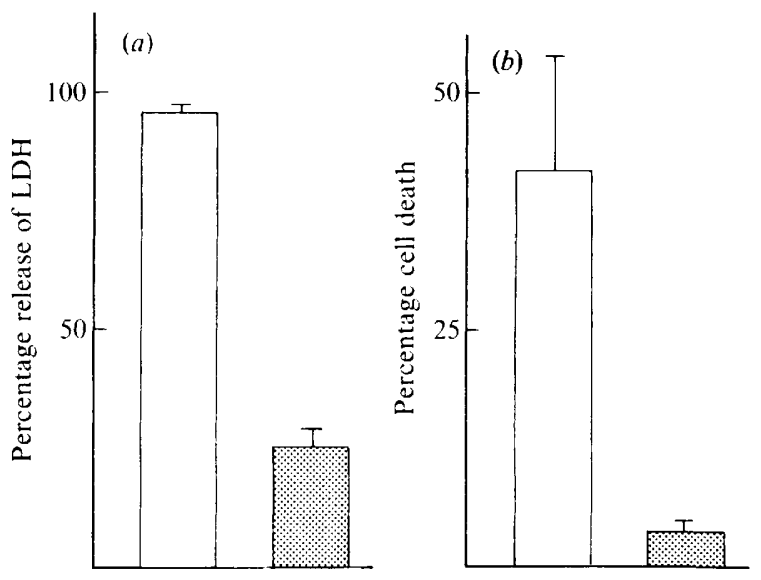

Fig. 5. (a) Percentage release of LDH ( $\square$ ) and arylsulphatase (因) following $30 \mathrm{~min}$ of exposure to purified toxin at $37^{\circ} \mathrm{C}$. Mean $\pm \mathrm{SEM}$ of three experiments. $P<0.001$ for comparison of LDH release with arylsulphatase release. (b) Percentage cell death (failure to exclude trypan blue) after momentary ( 5 to $10 \mathrm{~s}$ ) exposure to purified toxin ( $\square$ ) or buffer (용) followed by immediate cold dilution, washing and rewarming. Mean \pm SEM of four experiments. Excess cell death attributable to toxin was $37.5 \pm 11.6 \%(P<0.05$ by single sample $t$-test).

produced a much higher rate of cell death than was seen in cells not exposed to toxin. A control experiment using toxin at $0{ }^{\circ} \mathrm{C}$ for $30 \mathrm{~min}$ showed only $5.4 \% \mathrm{LDH}$ release, suggesting again that contact with cells at $37^{\circ} \mathrm{C}$ was needed for full toxin activity.

\section{Discussion}

Bacterial release of exoproteins may contribute to the pathogenesis of many bacterial infections. Direct damage to surrounding tissue is perhaps the most familiar effect of such toxins; systemic effects from specific vascular or neuronal toxicity are also well recognized. Less well studied and more indirect is the potential pathogenic contribution of exotoxins which attack host phagocytic cells. These may exert their pathogenic activity primarily by depressing the ability of the phagocytes to contend with bacterial invaders, and secondarily by eliciting phagocytic release of oxygen metabolites or digestive enzymes which may further exacerbate local host tissue damage.

The leucotoxin produced by $P$. haemolytica has an evident depressive effect on phagocytic cell function through inhibition of the respiratory burst of oxidative metabolism (Chang \& Renshaw, 1986). We have previously found this effect to be preventable by the use of antiserum raised against whole $P$. haemolytica (Styrt $e t$ $a l ., 1990)$. In the studies reported here, we found that keeping cells chilled throughout the period of exposure to leucotoxin-containing culture supernatants prevented most of the cytotoxic effect; however, even a momentary exposure to toxin at $37^{\circ} \mathrm{C}$ caused irreversible granulocyte damage. We also found that leakage of granule enzymes such as arylsulphatase (which might be a marker for either neutrophils or eosinophils; Healy, 1982) could continue for many hours after granulocyte death appeared effectively complete. Release of activity associated with elastase, a neutrophil granule enzyme (Sklar et al., 1982), was also slower than the time course of cell death. While most of these studies were done with a crude leucotoxin preparation (culture supernatant), results of selected experiments repeated with the small amount of purified toxin available were generally confirmatory. While this finding does not establish whether the leucotoxin molecule is responsible for all of the effects seen with culture supernatants, it does suggest that the observed divergence between cytosol and granule enzyme release is a feature of the leucotoxin activity.

While investigation of the molecular mechanism of action and pathogenic role of $P$. haemolytica leucotoxin has been hampered by the difficulty of obtaining pure preparations with good biological activity, several tentative conclusions can be drawn regarding its structural and functional relationships to other bacterial exotoxins with cytotoxic activity. Although additional granule marker assays and ultrastructural studies would be needed for confirmation, our findings suggest that this leucotoxin is unlikely to act in a manner similar to that of streptolysin S (Densen \& Mandell, 1980; Alouf, 1980; Alouf \& Loridan, 1988) or staphylococcal alpha toxin (Densen \& Mandell, 1980), which are thought to stimulate massive degranulation or directly lyse granules as part of their activity. Staphylococcal leucocidin is also thought to induce degranulation (Densen \& Mandell, 1980 ) but requires two protein components for activity which is lost when these are separated during purification (Noda et al., 1980; Noda \& Kato, 1988); a similar requirement might explain the difficulty of purifying $P$. haemolytica leucotoxin in an active form. Another possible analogy is to the leucocidin recently described as a product of Fusobacterium necrophorum, which itself requires further characterization (Emery et al., 1984; Emery \& Vaughan, 1986; Kanoe et al., 1988). The reported sequence homology between $P$. haemolytica leucotoxin and Escherichia coli alpha haemolysin (Lo et al., 1987; Strathdee \& Lo, 1987) would also suggest a common mechanism of action, but we are not aware of any detailed studies of interactions between the $E$. coli haemolysin and granulocytes.

These findings have several implications both for understanding the molecular and cellular basis of 
leucotoxin/granulocyte interaction and for elucidating the pathophysiology of $P$. haemolytica infection. On the one hand, the rapid initiation of irreversible cell damage at $37^{\circ} \mathrm{C}$ and its attenuation by cold temperatures suggest that leucotoxin activity depends either on a contribution of metabolic activity by the host cell (e.g. endocytic internalization of the toxin) or on properties of the cell membrane or the toxin that might change with temperature (e.g. membrane viscosity or receptor conformation). On the other hand, the differing time courses of cytotoxicity and release of granule contents suggest a sequence of events which could begin with immediate suppression of neutrophil ability to combat the microorganism and progress to delayed granulocyte enzyme leakage contributing to ongoing tissue damage. While further investigation is needed for determination of in vivo relevance, additional studies in these areas may help to elucidate and eventually to manage the effects of interactions between host phagocytes and bacterial exoproducts.

We thank Diane Bannerman for expert manuscript preparation, and Dr Barrett Sugarman for helpful discussions.

This work was supported in part by Michigan State University and the United States Department of Agriculture (Special Grant 88-34116-3954), and presented in part at the 29th Interscience Conference on Antimicrobial Agents and Chemotherapy, Houston, USA (Abstract no. 176) and the 70th Conference of Research Workers in Animal Diseases, Chicago, USA (Abstract no. P49).

\section{References}

ALour, J. E. (1980). Streptococcal toxins (streptolysin O, streptolysin S, erythrogenic toxin). Pharmacology and Therapeutics 11, 661-717.

ALOUF, J. E. \& LORIDAN, C. (1988). Production, purification and assay of streptolysin S. Methods in Enzymology 165, 59-64.

Breider, M. W., Walker, R. D., Hopkins, F. M., Schultz, T. W. \& Bowersock, T. L. (1988). Pulmonary lesions induced by Pasteurella haemolytica in neutrophil sufficient and neutrophil deficient calves. Canadian Journal of Veterinary Research 52, 205-209.

Brown, G. B. \& Roth, J. A. (1990). Comparison of the response of bovine and human neutrophils to various stimuli. Veterinary Immunology and Immunopathology (in the Press).

Chang, Y. F. \& Renshaw, H. W. (1986). Pasteurella haemolytica leukotoxin: comparison of ${ }^{51}$ chromium-release, trypan blue dye exclusion, and luminol-dependent chemiluminescence-inhibition assays for sensitivity in detecting leukotoxin activity. American Journal of Veterinary Research 47, 134-138.

Chang, Y. F., Renshaw, H. W., Martens, R. J. \& Livingston, C. W., JR. (1986). Pasteurella haemolytica leukotoxin: chemiluminescent responses of peripheral blood leukocytes from several different mammalian species to leukotoxin- and opsonin-treated living and killed Pasteurella haemolytica and Staphylococcus aureus. American Journal of Veterinary Research 47, 67-74.
Clinkenbeard, K. D., Mosier, D. A., Timko, A. L. \& Confer, A. W. (1989). Effects of Pasteurella haemolytica leukotoxin on cultured bovine lymphoma cells. American Journal of Veterinary Research 50, 271-275.

Colton, T. (1974). Statistics in Medicine. Boston: Little, Brown \& Co.

Deneer, H. G. \& PotTer, A. A. (1989). Iron-repressible outermembrane proteins of Pasteurella haemolytica. Journal of General Microbiology 135, 435-443.

Densen, P. \& MANDell, G. L. (1980). Phagocyte strategy vs. microbial tactics. Reviews of Infectious Diseases 2, 817-836.

EMERY, D. L., DUfTY, J. H. \& Clark, S. L. (1984). Biochemical and functional properties of a leucocidin produced by several strains of Fusobacterium necrophorum. Australian Veterinary Journal 61, 382-387.

Emery, D. L. \& Vaughan, J. A. (1986). Generation of immunity against Fusobacterium necrophorum in mice inoculated with extracts containing leucocidin. Veterinary Microbiology 12, 255-268.

Fluharty, A. L. \& EDMond, J. (1978). Arylsulfatases A and B from human liver. Methods in Enzymology 50, 537-547.

Healy, P. J. (1982). Lysosomal hydrolase activity in leucocytes from cattle, sheep, goats, horses and pigs. Research in Veterinary Science 33, 275-279.

Kaehler, K. L., Markam, R. J. F., Muscoplat, C. C. \& Johnson, D. W. (1980). Evidence of cytocidal effects of Pasteurella haemolytica on bovine peripheral blood mononuclear leukocytes. American Journal of Veterinary Research 41, 1690-1693.

Kanoe, M., Yamamato, T., KaI, K. \& Blobel, H. (1988). Effects of leukocidin from Fusobacterium necrophorum on bovine peripheral leukocytes in vitro. Zentralblatt für Bakteriologie und Hygiene A268, 463-469.

Korzeniewski, C. \& CallewaerT, D. M. (1983). An enzyme-release assay for natural cytotoxicity. Journal of Immunological Methods 64, 313-320.

Lo, R. Y. C., Strathdee, C. A. \& Shewen, P. A. (1987). Nucleotide sequence of the leukotoxin genes of Pasteurella haemolytica A1. Infection and Immunity 55, 1987-1996.

Noda, M., Hirayama, T., Kato, I. \& Matsuda, F. (1980). Crystallization and properties of staphylococcal leukocidin. Biochimica et Biophysica Acta 633, 33-44.

Noda, M. \& Kato, I. (1988). Purification and crystallization of staphylococcal leukocidin. Methods in Enzymology 165, 22-33.

O'Brien, J. K. \& Duffus, W. P. H. (1987). Pasteurella haemolytica cytotoxin: relative susceptibility of bovine leukocytes. Veterinary Microbiology 13, 321-334.

Potter, A. A., Ready, K. \& Gilchrist, J. (1988). Purification of fimbriae from Pasteurella haemolytica A1. Microbial Pathogenesis 4, 311-316.

Sklar, L. A., McNeil, V. M., Jesaitis, A. J., Painter, R. G. \& Cochrane, C. G. (1982). A continuous, spectroscopic analysis of the kinetics of elastase secretion by neutrophils. Journal of Biological Chemistry 257, 5471-5475.

Slocombe, R. F., Malark, J., Ingersoll, R., Derksen, F. J. \& RoBinson, N. E. (1985). Importance of neutrophils in the pathogenesis of acute pneumonic pasteurellosis in calves. American Journal of Veterinary Research 46, 2253-2258.

StrathDeE, C. A. \& Lo, R. Y. C. (1987). Extensive homology between the leukotoxin of Pasteurella haemolytica $\mathrm{Al}$ and the alphahemolysin of Escherichia coli. Infection and Immunity 55, 3233-3236.

STYRT, B., JOHNSON, P. C. \& KlEMPNER, M. S. (1985). Differential lysis of plasma membranes and granules of human neutrophils by digitonin. Tissue \& Cell 17, 793-800.

StYrT, B., Walker, R. D., White, J. C., Daht, L. D. \& BakeR, J. C. (1990). Granulocyte plasma membrane damage by leukotoxic supernatant from Pasteurella haemolytica $\mathrm{A} 1$ and protection by immune serum. Canadian Journal of Veterinary Research 54, 146-150.

W ALKer, R. D., Hopkins, F. M., SChultZ, T. W., McCracken, M. D. \& MOORE, R. N. (1985). Changes in leukocyte populations in pulmonary lavage fluids of calves after inhalation of Pasteurella haemolytica. American Journal of Veterinary Research 46, 2429-2433. 